\title{
BIPLOT ANALYSIS OF LEAF RUST RESISTANCE IN PURE LINES SELECTED FROM EASTERN ANATOLIAN BREAD WHEAT LANDRACES OF TURKEY
}

\author{
Mevlut AKCURA ${ }^{1}$, Kadir AKAN², Onur HOCAOGLU $U^{1 *}$ \\ ${ }^{1}$ University of Canakkale Onsekiz, Mart, Faculty of Agriculture, Department of Field Crops, Canakkale, \\ TURKEY \\ ${ }^{2}$ University of Ahi Evran, Faculty of Agriculture, Department of Plant Protection, Kirsehir, TURKEY \\ * Corresponding author: onurhocaoglu@comu.edu.tr
}

Received: 06.04.2017

\begin{abstract}
The present research was conducted to determine the reactions of 42 pure lines selected from bread wheat landraces of Eastern Anatolia, Turkey, against the leaf rust (Puccinia triticina) disease under field conditions across 7 environments. G (Genotype), GE (Genotype Environment) biplot analysis method was used to determine the reactions of landraces against leaf rust disease. GGE-biplot graph created to assess leaf rust disease was explained a $78.12 \%$ of total variation. While E3 and E2 constituted the first and second mega environments respectively, the other four environments constituted the third and fourth mega environments. The lowest PC1 values and PC2 values close to 0.0 explaining the resistance of pure lines to leaf rust at best in the biplot. Reactions of landraces varied based on their distance from the Average Environment Axis (AEA). While the pure lines with the same or similar reactions in 7 experimental environments fell close to the axis, ones with different reactions in one or more environments were relatively distant. The pure lines of EA15 and EA19 were identified as the most resistant and stable genotypes in all environments when EA42 and EA41 were the most susceptible/stable genotypes in all environments. Pure lines that were resistant or moderately resistant at all seven tested environments should be useful for breeding wheat cultivars with resistance to leaf rust in Turkey.
\end{abstract}

Keywords: GGE-Biplot, Landraces, Leaf rust (Puccinia triticina), Pure line, Turkey

\section{INTRODUCTION}

Diversity of wheat in Turkey has a global role in providing important genetic resources for wheat breeding (Morgounov et al., 2016). It is also known that various civilizations in Anatolia used wheat intensely for different purposes. Being cultivated since time immemorial, wheat is a cultural crop in Turkey as old as history of humanity. Local wheat landraces has developed over time while as being adapted to their ecological and agricultural environment of Anatolia. The determination of these genetic resources is crucially important in plant breeding against the biotic and abiotic stress causing factors (Heitefuss, 2011; Yildiz, 2011) that limit the quality and quantity of wheat production worldwide.

Host plant resistance is the most reliable, efficient and economical way among the various approaches to manage crop diseases. Leaf rust, caused by Puccinia triticina, is one of the most important diseases of bread wheat in different countries. McCallum et al. (2016) reported that cereal rust pathogens are often able to change genetically, through mutation and sexual or asexual recombination, to become virulent to resistance genes present in the host. The results of more than 75 years of annual virulence surveys of $P$. triticina in Canada demonstrated the diverse and rapidly changing nature of these populations (McCallum et al., 2016). The fact that the plant breeders need to invest efforts to identify new and diverse sources of resistance are important in relation to leaf rust resistant/tolerant breeding. Thus, Turkish bread wheat landraces are among the best genetic materials in resistant breeding programs.

The study of host (Genotype Environment Interaction, GEI) interactions is essential in plant pathology and other agricultural researchers, but efficient breeding for disease resistance depends on a good understanding of the hostpathogen relationships. Thus, plant breeders commonly grow breeding material in different locations and years to determine whether or not environment affects the magnitude of specific quantitative traits of host genotypes, such as yield and disease severity (Piepho, 1996; Madden et al., 2007). 
Most breeding programs face complex megaenvironments with unpredictable GEI and genotype evaluation based on mean performance and stability has been a perennial problem and challenge (Yan and Kang, 2003). GGE biplot analysis results can discriminate between expected and realized responses of genotypes and has been widely used in recent years to determine the stability of disease resistance through multi-environment trials. GGE biplot is an effective method to fully examine the data. The biplot method originated with Gabriel (1971) and its use was later expanded by Kempton (1984) and Zobel et al. (1988). The extensive usefulness of GGE biplot, where G (genotype effect) and GE (genotype-byenvironment effect), has only recently been elucidated (Yan et al., 2000). GGE biplot method enables graphical evaluation of the relation among the test environments, genotypes, and the GEIs (Sharma et al., 2016). In addition, GGE biplot usually used to (i) evaluate whichwon-where pattern, (ii) investigate mega environment, (iii) determine mean performance and stability of genotypes in multi environment yield trials (Yan and Falk, 2002). Lately, GGE biplot has been used to characterize and determine stability of germplasm, breeding lines and cultivars resistance to diseases such as anthracnose in water yam (Egesi et al., 2009), chocolate spot disease in faba bean (Villegas-Fernandez et al., 2009), white rust in Brassica (Sandhu et al., 2015), Fusarium udum in pigeonpea (Sharma et al., 2016), dry root rot an stunt disease in chickpea (Kumar et al., 2017), yellow mosaic disease in mungbean (Parihar et al., 2017), grey leaf spot in maize (Acorsi et al., 2017) grain yields of maize hybrids (Ilker et al., 2009; Mitrović et al., 2012). Leaf rust, (caused by Puccinia triticina) is encountered in wheat cultivation growing areas in coastal regions, Southeastern Anatolia, Çukurova, Middle Black Sea, Southern Marmara and Thrace regions of Turkey.

Therefore, the present study was conducted with the objectives (i) to evaluate bread wheat pure lines resistant to leaf rust (Puccinia triticina) trough multi-environment (both years and locations) and identify stability of their resistance (ii) to facilitate visual comparison among pure lines and environments (iii) to select genetic material for bread wheat improvement programs of Turkey.

\section{MATERIALS AND METHODS}

In present study, 42 pure lines selected from wheat landraces collected from Erzurum, Hakkari, Van, Kars and Gümüşhane provinces of Eastern Anatolia were used as the plant material. Experiments were conducted according to incomplete block design in 2011-2014 growing seasons at Çanakkale, Edirne and Samsun locations in two replications. However, since the disease didn't reach to desired levels under natural epidemy conditions in Samsun location in 2012-2013 and 20132014 growing seasons, this part of the study was excluded. So that, 7 environments were used in the present study.

Long-term average precipitation of Çanakkale location was $529.4 \mathrm{~mm}$ and long-term average temperature of April and May in which leaf rust disease is developed was 12.6 and $17.6{ }^{\circ} \mathrm{C}$; long-term average precipitation of Edirne location was $484.5 \mathrm{~mm}$ and long-term average temperature of April and May was 12.8 and $18.1^{\circ} \mathrm{C}$; longterm average precipitation of Samsun location was 534.7 $\mathrm{mm}$ and long-term average temperature of April and May was 11.4 and $15.6{ }^{\circ} \mathrm{C}$.

Experimental locations were selected from the wheat cultivated locations infested with leaf rust disease at various levels. Experimental material were sown manually in the first quarter of November of each growing season over $1 \mathrm{~m}$-long rows with two replications in each location. Disease development was encountered under natural epidemy conditions, additional disease inoculation was not performed. For the spread of disease and more homogeneous assessment, susceptible control cultivars (Thatcher and Morocco) were sown repeatedly in one row after each 10 rows of experimental material. In addition, susceptible Gün 91 cultivar was also sown once in each 6 rows in every experimental environment for the same purpose.

Table 1. Genotypes in differential set and resistance genes they include

\begin{tabular}{llllll}
\hline No & Genotype & Resistance gene & No & Genotype & Resistance gene \\
\hline 1 & RL 6003 & $\operatorname{Lrl}$ & 11 & RL 6008 & $\operatorname{Lr} 17$ \\
2 & RL 6016 & $\operatorname{Lr} 2 a$ & 12 & RL 6049 & $\operatorname{Lr30}$ \\
3 & RL 6047 & $\operatorname{Lr} 2 c$ & 13 & RL6051 & $\operatorname{Lr~B}$ \\
4 & RL 6002 & $\operatorname{Lr} 3$ & 14 & RL 6004 & $\operatorname{Lr~10}$ \\
5 & RL 6010 & $\operatorname{Lr} 9$ & 15 & RL 6013 & $\operatorname{Lr} 14 a$ \\
6 & RL 6005 & $\operatorname{Lr} 16$ & 16 & RL 6009 & $\operatorname{Lr} 18$ \\
7 & RL 6064 & $\operatorname{Lr} 24$ & 17 & RL 6042 & $\operatorname{Lr~3bg}$ \\
8 & RL 6078 & $\operatorname{Lr} 26$ & 18 & RL 6006 & $\operatorname{Lr~14b}$ \\
9 & RL 6007 & $\operatorname{Lr} 3 k a$ & 19 & RL 6092 & $\operatorname{Lr~20}$ \\
10 & RL 6053 & $\operatorname{Lr} 11$ & 20 & RL 6079 & $\operatorname{Lr~28}$ \\
\hline
\end{tabular}

Differential set composed of 20 genotypes and including different leaf rust resistance genes were used to identify which resistance gene is virulent/avirulant to disease race/races (Table 1). The differential set was also sown within the research material.

Disease assessments were initiated when the susceptible control cultivars of Thatcher and Morocco 
reached to $80 \mathrm{~S}$ level and assessments were made 3 times in 10-day intervals. Disease infections were recorded in accordance with Modified Cobb scale (Peterson et al. 1948). The disease in Thatcher and Morocco cultivars used as the susceptible control cultivar in each location which was identified as $100 \mathrm{~S}$. Such a finding revealed that disease infection was sufficient, successful and disease reactions of the test materials used in this study could be accurately assessed. The replication with the highest than score was taken as the basis. The response to infection was also scored: $\mathrm{R}=$ resistant, smaller uredia surrounded by necrotic tissues; MR (moderately resistant): smaller uredia surrounded by necrotic tissues; MS (moderately susceptible): moderate sized uredia without necrotic tissues; S (susceptible): large uredia without necrotic tissues (Akin et al., 2008). Then the entries were classified per their CI values: Immune: 0, Resistant: 0.15.0; Moderately Resistant: 5.01-20.0; Moderately Susceptible: 20.1-40.0; Susceptible: 40.1-100.

Before biplot analysis, \% values of disease reactions of pure lines were subjected to arcsine transformation (Gomez and Gomez, 1984). The GGE-biplot technique was used to create a genotype-focused GGE-biplot graph to assess the reactions of the test materials against leaf rust statistically and to select resistant materials for national/regional disease resistance genetic sources (Yan and Falk, 2002; Yan, 2014). The statistical theory of GGE biplot methodology was explained in detail by Yan (2014).

The GGE model used to determine the resistance of pure line across environments was:

$$
\mathrm{Y}_{i j}-\mu-\beta_{j}=\lambda_{1} \xi_{i 1} \eta_{1 j}+\lambda_{2} \xi_{i 2} \eta_{2 j}+\text { aij }
$$

where

$\mathrm{Y}_{i j}=$ the expected value for pure line $i$ in environment $j ; \mu=$ the grand mean of all pure line - environment combinations; $\beta_{j}=$ the main effect of environment $j ; \lambda_{1}$ and $\lambda_{2}$ are the singular values of first and second largest principal components, $\mathrm{PC} 1$ and $\mathrm{PC} 2$, respectively; $\xi_{i 1}$ and $\xi_{i 2}$ are the eigenvectors of pure line $i$ for PC1 and PC2, respectively; $\eta_{1 j}$ and $\eta_{2 j}$ are the eigenvectors of environment $j$ for $\mathrm{PC} 1$ and $\mathrm{PC} 2$, respectively, and $\varepsilon_{i j}=$ the residue for each pure line-environment combination not explained by PC1 and PC2.

Genotype-focused GGE biplot graphs (Figure 1, 2 and 3) were created with GGE biplot technique (Yan and Falk, 2002; Yan, 2014), using GGEbiplotGUI module of R Package (R Core Team, 2013; Frutos et al., 2014)

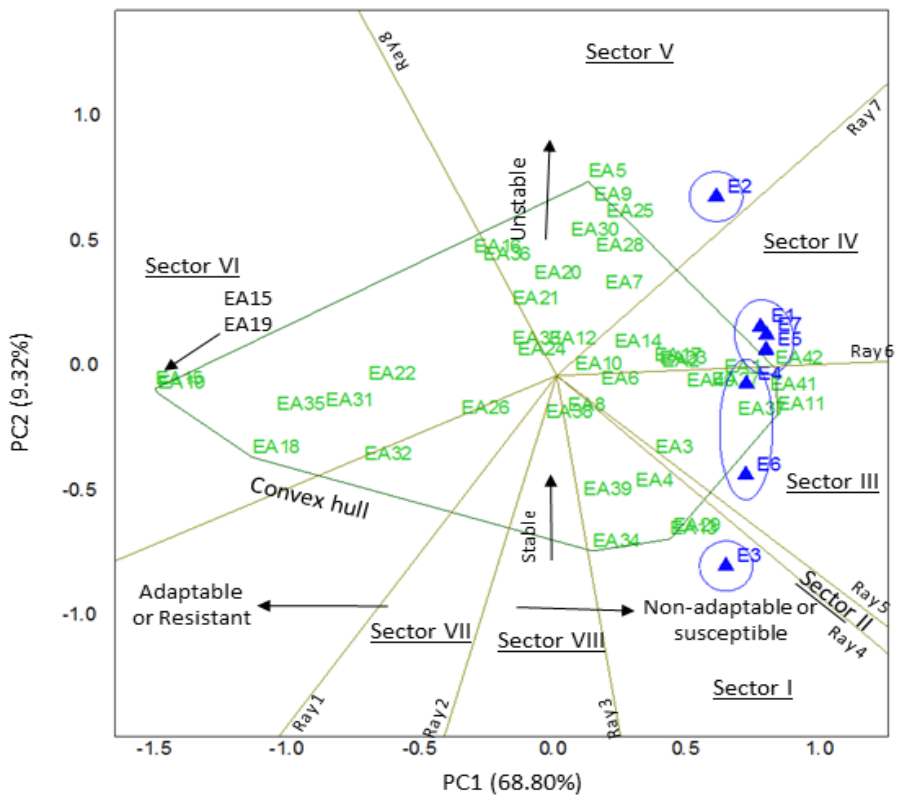

Figure 1. GGE biplot based on leaf rust disease scores indicating susceptibility of 42 bread lines selected from landraces across seven environments.

\section{RESULTS}

The first two principal components of the GGE biplot for leaf rust disease data explained $78.12 \%(68.80 \%$ and $9.32 \%$ by $\mathrm{PC} 1$ and $\mathrm{PC} 2$ respectively) of total variation (Figure 1). The symmetrical singular value partitioning method was used to display the biplot of PC1 scores plotted against PC2 scores for both pure lines and environments. The polygon was drawn on pure lines that were placed furthest from the biplot origin such that all other pure lines were included (Yan and Kang, 2003). Then, biplot were divided into sectors by perpendicular lines of each side of the polygon. There were eight sectors 
in Figure 1. Sector II, Sector VII and Sector VIII had not only genotypes but also environments. In Figure 1, four groups of environments are obvious: E3 in the sector I (mega environment 1), E4 and E6 in the sector III (mega environment 2), E1, E7 and E5 in the sector IV (mega environment 3 ) and $\mathrm{E} 2$ in the sector $\mathrm{V}$ (mega environment 4). In present study, all environments had positive PC1 values and located in the right side of biplot (Figure 1 and 2).

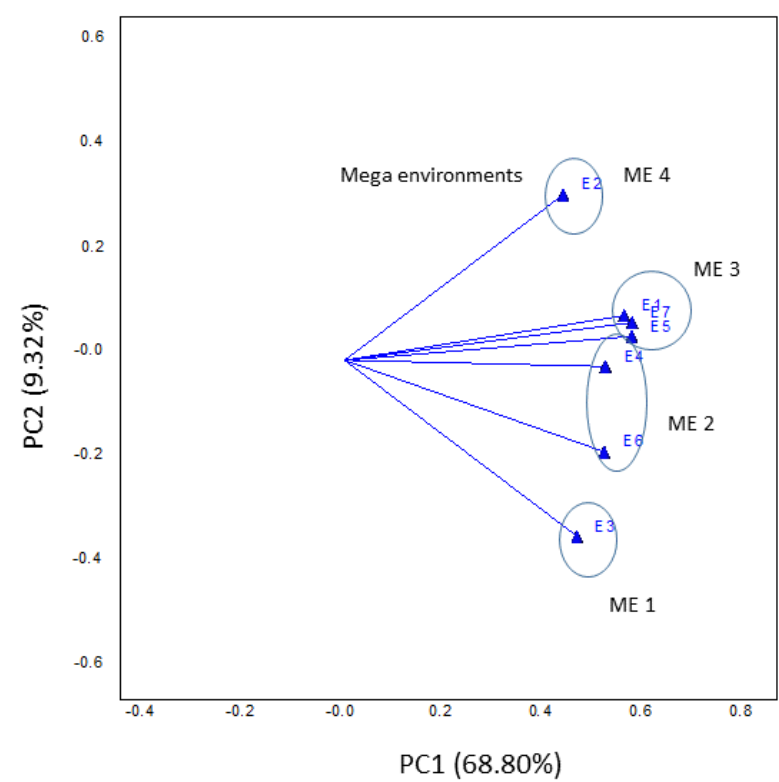

Figure 2. The vector view of the GGE biplot shows the interrelationships among the test environments

The polygon is used as an instrument to compare adjacent vertex pure lines. The vertex pure lines in some sectors (I, III and IV) were ranked among highestsusceptible pure lines in environments that fell in that sector. In Figure 1, EA18, EA34, EA29, EA13, EA11, EA41, EA42, EA25, EA9, EA5, EA19 and EA15 were the vertex pure lines. These vertex pure lines in the sectors have the highest reaction values or susceptibility for all environments within that sector due to amount and direction of their distance from the biplot origin. EA15 and EA19 were placed at the opposite side and far away from all environments which indicates that they were the most resistant genotypes in this study. Contrarily, EA29 and EA13 were most susceptible genotypes at E3 environment; and EA11, EA41 and EA42 were the most susceptible genotypes at other environments except E2 and E3. A pure line located near the origin would rank the same in all environments and was not responsive to the environments. Figure 1 also indicated the following EA13 and EA29 were like EA34; EA11 and EA41 were like EA42; EA25 and EA9 were like EA5; EA19 was highly similar to EA15.

Figure 3 represented the relation among the environments. The angle between the vectors of two environments is related to correlation coefficient between them (Sandhu et al., 2015). Based on the cosine of angles of environment vectors, E3 and E2 are located far away from both each other and other environments. Other five environments located relatively closer. There were four mega groups in Figure 3. The four-mega-environment suggestion in Figure 2 related with the geographical distribution of environments. E3 environment (Samsun) is located in Blacksea region which is much cooler than Çanakkale (E1, E4 and E6) and Edirne (E2, E5 and E7) environments which are located in Trakya region.

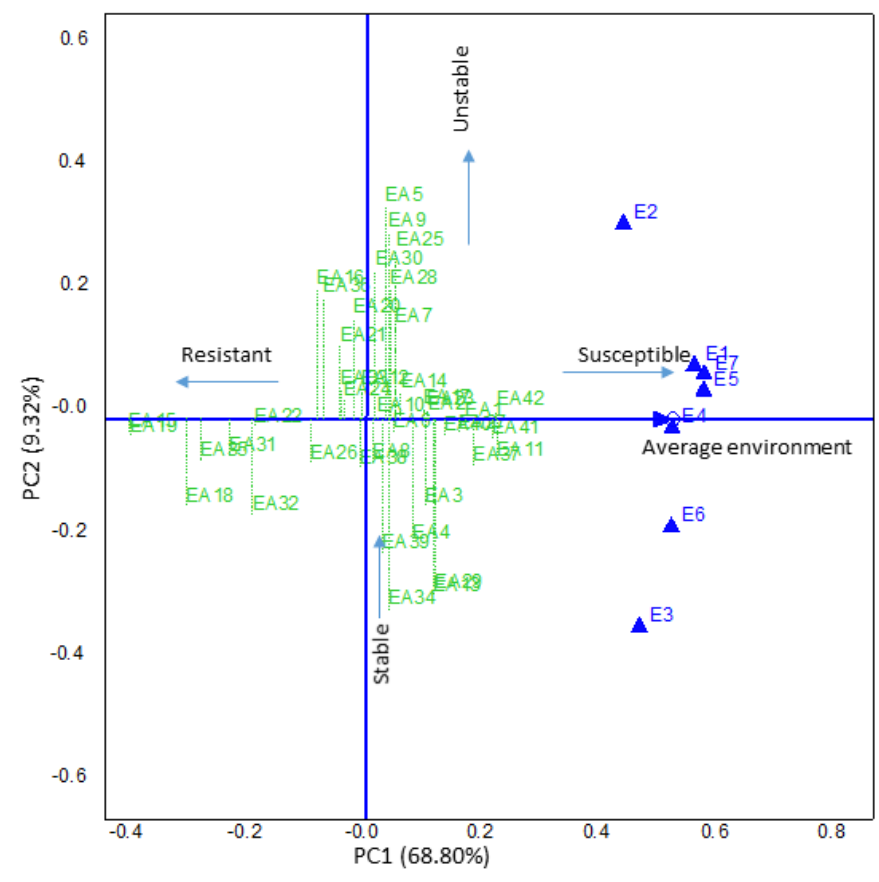

Figure 3. Average Environment Axes (AEA) view of the GGE-biplot based on leaf rust scores of 42 bread lines selected from landraces across seven environments. 


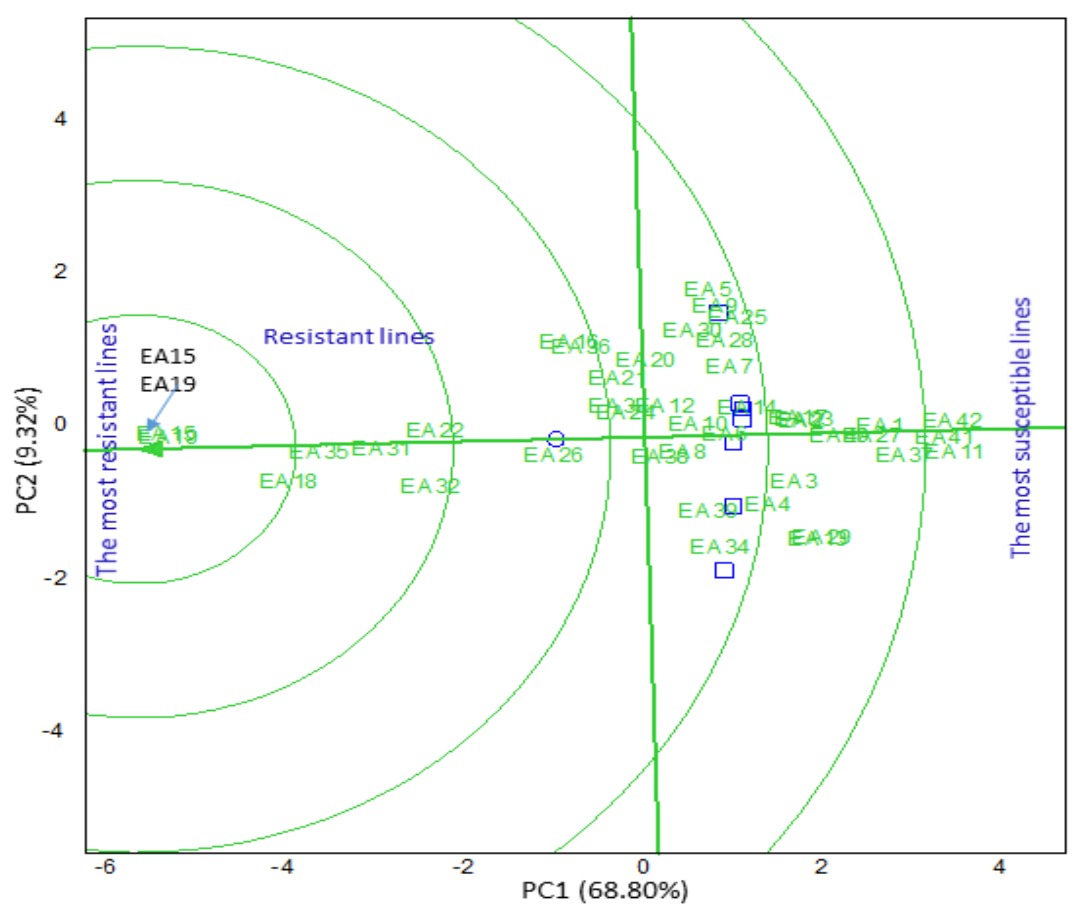

Figure 4. Comparison of all pure lines with the ideal genotype for leaf rust across environments.

The average environment (AEA) is indicated by a small circle in Figure 2, which is the line that passes through the biplot origin and the average environment view of the biplot facilitates this (Figure 3). In addition, the AEA abscissa represents the mean resistance, and the AEA ordinate represents the stability of genotypes across all environments. As far as stability and resistance is related EA15, EA19, EA22, EA31 and EA35 showed consistently resistant performance at different locations over the years, showing wider adaptability. On the contrary, some genotypes, notably EA5, EA9, EA25 and EA34, were both susceptible and unstable. On the other hand, figure 3 revealed that a group of pure lines, which was represented by EA40, EA27 and EA41 were both susceptible and relatively stable across the environments. (Figure 3).

The most resistant pure line (ideal genotype) in terms of leaf rust reaction should have the lowest possible mean reaction and the highest possible stability (i.e., zero contribution to GE). This ideal genotype is defined by the small circle in Figure 4. The environments were represented by square icon for clearness. The desirability of the pure line was judged by their proximity to this "ideal" genotype. Thus, EA15 and EA19 were the most desirable and EA42 the most undesirable genotypes. Based on Figure 4, the second and third most desirable genotypes would be EA35 and EA18, which were near to EA 15 and EA19.

The biplot in Figure 4 was the same as in Figure 1 but it was designed to rank the genotypes based on both mean leaf rust reactions and stability. The concentric circles help to rank the genotypes based on their distances to the ideal genotype. The pure lines closest to the most resistant genotypes were EA35, EA31, EA22 and EA32.
The biplot origin also represented a virtual genotype that assumes the grand mean values and zero contribution additive effect of genotype (G) and multiplicative interactions (GE) (Sandhu et al., 2015). The vector length of a genotype from the origin of biplot was due to the contribution of $\mathrm{G}$ or GE or both. Those genotypes that were located close to the biplot origin contributed little to either G or GE, viz., EA10, EA24 and EA8 and pure lines distant from the origin indicated more contribution of $\mathrm{G}$ or GE or both. Therefore, pure lines with the longest vectors were either the most resistant (EA15 and EA19) or the most susceptible (EA41) or most unstable (EA34 and EA5).

\section{DISCUSSION}

Multi-environment testing of 42 pure lines revealed significant differences in pure lines and environments. The reaction of pure lines to leaf rust disease was diverse in different environments indicating differential magnitude of virulence of the pathogen population or other external factors. Some pure lines showed resistance at some environments, while being susceptible at other environments. When genotypes evaluated in multienvironment trials, shifts in relative ranking of genotype by environment interactions often occur (Alam et al., 2014; Parihar et al., 2017).

The disease in Thatcher and Morocco cultivars used as susceptible control cultivar in all seven environments was identified as $100 \mathrm{~S}$. Such a finding revealed that disease infection was sufficient and successful and disease reactions of bread wheat pure lines used in this study could be accurately assessed. 
Table 2. Leaf rust disease reactions of test materials in different environments

\begin{tabular}{|c|c|c|c|c|c|c|c|c|c|c|c|c|c|c|c|}
\hline \multirow{3}{*}{ No } & \multirow{3}{*}{ Landrace Name (TR) } & \multicolumn{14}{|c|}{ Environments" } \\
\hline & & \multicolumn{2}{|c|}{ E1 } & \multicolumn{2}{|c|}{ E2 } & \multicolumn{2}{|c|}{ E3 } & \multicolumn{2}{|c|}{ E4 } & \multicolumn{2}{|c|}{ E5 } & \multicolumn{2}{|c|}{ E6 } & \multicolumn{2}{|c|}{ E7 } \\
\hline & & CI & RG & $\mathbf{C I}$ & RG & CI & RG & CI & RG & CI & RG & $\mathrm{CI}$ & RG & CI & RG \\
\hline EA1 & ERZURUM 32790/1 & 65 & $\mathrm{~S}$ & 85 & $\mathrm{~S}$ & 70 & $\mathrm{~S}$ & 65 & $\mathrm{~S}$ & 65 & $\mathrm{~S}$ & 75 & $\mathrm{~S}$ & 70 & $\mathrm{~S}$ \\
\hline EA2 & ERZURUM 45370/5 & 55 & S & 80 & $S$ & 65 & S & 70 & $\mathrm{~S}$ & 75 & S & 55 & $\mathrm{~S}$ & 45 & $\mathrm{~S}$ \\
\hline EA3 & ERZURUM 45370/6 & 55 & $\mathrm{~S}$ & 55 & S & 65 & $\mathrm{~S}$ & 65 & $\mathrm{~S}$ & 45 & $\mathrm{~S}$ & 75 & $\mathrm{~S}$ & 70 & $\mathrm{~S}$ \\
\hline EA4 & ERZURUM 32893/1 & 45 & S & 20 & MR & 50 & S & 80 & S & 70 & $S$ & 70 & S & 60 & $\mathrm{~S}$ \\
\hline EA5 & ERZURUM 45370/4 & 55 & S & 80 & S & 20 & MR & 55 & $\mathrm{~S}$ & 65 & $S$ & 30 & MS & 65 & $\mathrm{~S}$ \\
\hline EA6 & ERZURUM 45370/6 & 45 & S & 55 & $\mathrm{~S}$ & 55 & S & 50 & S & 70 & $S$ & 50 & $S$ & 55 & $\mathrm{~S}$ \\
\hline EA7 & ERZURUM 32655/1 & 45 & S & 65 & $S$ & 20 & MR & 50 & $\mathrm{~S}$ & 70 & $\mathrm{~S}$ & 70 & $\mathrm{~S}$ & 70 & $\mathrm{~S}$ \\
\hline EA8 & ERZURUM 32780/3 & 55 & S & 55 & S & 55 & $\mathrm{~S}$ & 60 & S & 40 & $\mathrm{~S}$ & 55 & S & 5 & $\mathrm{R}$ \\
\hline EA9 & ERZURUM 32846/4 & 60 & S & 85 & S & 20 & MR & 55 & $\mathrm{~S}$ & 60 & S & 50 & $\mathrm{~S}$ & 60 & $\mathrm{~S}$ \\
\hline EA10 & GÜMÜŞHANE 14861/1 & 45 & S & 55 & S & 45 & S & 55 & $S$ & 55 & $S$ & 55 & $\mathrm{~S}$ & 60 & $\mathrm{~S}$ \\
\hline EA11 & GÜMÜŞHANE 14861/4 & 70 & S & 90 & S & 85 & S & 70 & $S$ & 75 & $S$ & 85 & $\mathrm{~S}$ & 75 & $\mathrm{~S}$ \\
\hline EA12 & GÜMÜŞHANE 14861/6 & 55 & S & 20 & MR & 20 & MR & 55 & $\mathrm{~S}$ & 65 & $\mathrm{~S}$ & 45 & $\mathrm{~S}$ & 65 & $\mathrm{~S}$ \\
\hline EA13 & GÜMÜŞHHANE 46871/1 & 55 & S & 20 & MR & 70 & $\mathrm{~S}$ & 80 & S & 65 & $S$ & 75 & S & 70 & $\mathrm{~S}$ \\
\hline EA14 & GÜMÜŞHANE 48039/6 & 60 & S & 45 & S & 60 & S & 65 & $\mathrm{~S}$ & 70 & S & 20 & MR & 70 & $\mathrm{~S}$ \\
\hline EA15 & HAKKARİ 47981/1 & 0 & $\mathrm{I}$ & 0 & I & 0 & I & 0 & I & 5 & $\mathrm{R}$ & 5 & $\mathrm{R}$ & 5 & $\mathrm{R}$ \\
\hline EA16 & HAKKARİ 46763/1 & 45 & $\mathrm{~S}$ & 55 & $\mathrm{~S}$ & 20 & MR & 55 & $\mathrm{~S}$ & 40 & $S$ & 20 & MR & 40 & $\mathrm{~S}$ \\
\hline EA17 & HAKKARİ 47988/4 & 70 & S & 60 & S & 60 & S & 55 & $\mathrm{~S}$ & 50 & $\mathrm{~S}$ & 60 & $\mathrm{~S}$ & 70 & $\mathrm{~S}$ \\
\hline EA18 & HAKKARİ 47982/5 & 5 & $\mathrm{R}$ & 5 & $\mathrm{R}$ & 5 & $\mathrm{R}$ & 40 & $S$ & 5 & $\mathrm{R}$ & 40 & $\mathrm{~S}$ & 5 & $\mathrm{R}$ \\
\hline EA19 & HAKKARİ 47981/4 & 5 & $\mathrm{R}$ & 5 & $\mathrm{R}$ & 5 & $\mathrm{R}$ & 5 & $\mathrm{R}$ & 5 & $\mathrm{R}$ & 5 & $\mathrm{R}$ & 5 & $\mathrm{R}$ \\
\hline EA20 & HAKKARİ 47987/4 & 50 & $S$ & 50 & S & 20 & MR & 80 & $\mathrm{~S}$ & 45 & $\mathrm{~S}$ & 30 & MS & 45 & $\mathrm{~S}$ \\
\hline EA21 & KARS 48025/6 & 55 & S & 20 & MR & 20 & MR & 55 & S & 60 & S & 20 & MR & 60 & $\mathrm{~S}$ \\
\hline EA22 & KARS 46851/1 & 40 & S & 15 & MR & 20 & MR & 40 & $\mathrm{~S}$ & 20 & MR & 20 & MR & 20 & MR \\
\hline EA23 & KARS 45904/6 & 60 & S & 20 & MR & 20 & MR & 60 & $\mathrm{~S}$ & 85 & S & 75 & $\mathrm{~S}$ & 85 & $\mathrm{~S}$ \\
\hline EA24 & VAN $45410 / 4$ & 65 & S & 20 & MR & 20 & MR & 55 & $\mathrm{~S}$ & 45 & $\mathrm{~S}$ & 45 & $\mathrm{~S}$ & 45 & $\mathrm{~S}$ \\
\hline EA25 & VAN $47966 / 7$ & 60 & S & 80 & $S$ & 20 & MR & 70 & S & 55 & S & 45 & S & 55 & S \\
\hline EA26 & VAN $45938 / 5$ & 35 & MS & 40 & S & 45 & S & 80 & S & 20 & MR & 30 & MS & 20 & MR \\
\hline EA27 & VAN 45398/6 & 45 & S & 75 & S & 65 & S & 70 & S & 70 & S & 75 & S & 85 & $\mathrm{~S}$ \\
\hline EA28 & VAN $45409 / 5$ & 55 & S & 70 & S & 20 & MR & 80 & $\mathrm{~S}$ & 45 & $\mathrm{~S}$ & 50 & $\mathrm{~S}$ & 55 & $\mathrm{~S}$ \\
\hline EA29 & VAN $45410 / 5$ & 60 & S & 20 & MR & 75 & $\mathrm{~S}$ & 80 & S & 70 & S & 60 & S & 70 & $\mathrm{~S}$ \\
\hline EA30 & VAN 45402/4 & 65 & S & 65 & S & 20 & MR & 50 & $\mathrm{~S}$ & 55 & S & 45 & $\mathrm{~S}$ & 60 & $\mathrm{~S}$ \\
\hline EA31 & VAN 47966/3 & 30 & MS & 10 & MR & 15 & MR & 40 & S & 15 & MR & 30 & MS & 15 & MR \\
\hline EA32 & VAN 47993/6 & 40 & S & 10 & MR & 40 & $\mathrm{~S}$ & 35 & MS & 15 & MR & 30 & MS & 20 & MR \\
\hline EA33 & VAN $32275 / 5$ & 55 & S & 20 & MR & 20 & MR & 70 & S & 55 & $S$ & 40 & $\mathrm{~S}$ & 55 & $S$ \\
\hline EA34 & VAN $48313 / 5$ & 55 & S & 15 & MR & 75 & $\mathrm{~S}$ & 50 & $\mathrm{~S}$ & 60 & S & 60 & $\mathrm{~S}$ & 55 & $\mathrm{~S}$ \\
\hline EA35 & VAN 47993/2 & 30 & MS & 10 & MR & 25 & MS & 30 & MS & 10 & MR & 5 & $\mathrm{R}$ & 5 & $\mathrm{R}$ \\
\hline EA36 & VAN 47995/3 & 45 & S & 50 & S & 20 & MR & 5 & $\mathrm{R}$ & 40 & $S$ & 20 & MR & 60 & $\mathrm{~S}$ \\
\hline EA37 & VAN 47966/5 & 70 & S & 85 & S & 85 & $\mathrm{~S}$ & 65 & S & 60 & $S$ & 80 & $\mathrm{~S}$ & 65 & $\mathrm{~S}$ \\
\hline EA38 & VAN $45399 / 2$ & 55 & S & 20 & MR & 55 & S & 60 & S & 60 & S & 20 & MR & 55 & $\mathrm{~S}$ \\
\hline EA39 & VAN 47995/5 & 55 & S & 20 & MR & 65 & S & 60 & S & 55 & S & 50 & $\mathrm{~S}$ & 50 & $\mathrm{~S}$ \\
\hline EA40 & VAN 45402/1 & 60 & S & 70 & S & 70 & S & 70 & S & 70 & $S$ & 55 & $\mathrm{~S}$ & 60 & $\mathrm{~S}$ \\
\hline EA41 & VAN 47995/4 & 65 & S & 70 & S & 60 & $\mathrm{~S}$ & 75 & S & 80 & S & 90 & $\mathrm{~S}$ & 80 & $\mathrm{~S}$ \\
\hline EA42 & VAN 39676/4 & 75 & S & 75 & $S$ & 70 & S & 85 & S & 85 & S & 70 & $\mathrm{~S}$ & 70 & $S$ \\
\hline
\end{tabular}

": Classification based on CI values were : R = resistant, smaller uredia surrounded by necrotic tissues; MR (moderately resistant): smaller uredia surrounded by necrotic tissues; MS (moderately susceptible): moderate sized uredia without necrotic tissues; S (susceptible): large uredia without necrotic tissues (Akin et al., 2008). CI: Coefficients of Infection; RG: Reaction of Group; Locations; E1: Çanakkale 2012; E2: Edirne 2012; E3: Samsun 2012; E4: Çanakkale 2013; E5: Edirne 2013; E6: Çanakkale 2014; E7 Edirne 2014

Differential set composed of 20 genotypes was used to identify the resistance genes on which leaf rust disease is effective in each experimental environment (Table 2). In all 5 experimental environments in 2011-2012 and 20122013 growing seasons, brown rust disease population was virulent on $\operatorname{Lr} 1, \operatorname{Lr} 2 c, L r 3, L r 16, L r 26, L r 3 k a, L r 17, L r 30$, LrB, Lr10, Lr14a, Lr18, Lr3bg, Lr14b, Lr20 and Lr28 resistance genes and avirulent on $L r 2 a, L r 9, L r 24$ and Lrl1 resistance genes.
On the other hand, in two environments of 2014 growing season, leaf rust disease population was virulent on Lr1, Lr2a, Lr2c, Lr3, Lr16, Lr26, Lr3ka, Lr17a, Lr30, LrB, Lr10, Lr14a, Lr18, Lr3bg, Lr14b, Lr20 and Lr28 resistance genes and avirulent on $\operatorname{Lr} 9, \operatorname{Lr} 24$ and $L r 11$ resistance genes.

To analyze disease data from multi-environment trials can be one of the big challenges due to variability in 
testing conditions and assessment methods (Lillemo et al., 2010). GGE analysis is widely used for the analysis of GxE interaction in multi environment yield trials (Yan and Kang, 2003; Yan, 2014; Kaplan et al., 2017). It has gained popularity since the resulting biplot gives a graphical display of which-won-where pattern and makes it easy to identify group of environments with the same winners.

This is the first study which carried out to evaluate leaf rust reaction across different environments using GGE biplot. This study has shown that evaluating wheat germplasm in multiple environments can be an efficient way to identify lines with stable/unstable, resistance/susceptible to leaf rust disease that is potentially race-nonspecific and durable in nature using GGE biplot. The GGE biplot analysis portrayed that 14 of 42 genotypes were in the left of biplot origin, which may be considered as from resistant to moderately resistant for leaf rust reaction across the environments. In other words, the genotypes far from the environments are possibly the ones negatively correlating with all environments, consequently assessed as the most resistant genotypes. In this way, genotypes with the least disease reactions generally have low PC1 value and a PC2 value close to 0.0 (Figure 1). Neither of the environments fell in the sectors with L19, L15 and L18 vertex pure lines which are located in the left side of biplots. This indicates that these vertex pure lines were the most resistant in some or all the environments. Other vertex pure lines in which most of them were susceptible, fell into some of environments on other sectors. To generalize, vertex pure lines are the most responsive genotypes; they are the resistant or else the susceptible pure lines in some or all the test environments.

Furthermore, GGE biplot analysis suggested that the environments used to examine the reactions of different pure lines against the leaf rust disease could be separated into four mega-environments based on coefficients of infection of leaf rust reaction. The environments which had an acute angle in the GGE biplot suggested a parallel reaction of genotypes (Yan, 2014). Accordingly, different pure lines should be selected using different selection strategies for environments that are favorable to susceptible vs. moderately susceptible vs. less susceptible reactions (Parihar et al., 2017). Therefore, E3 and E2 environments being distant from other testing environments were ideal test environments for leaf rust reactions based on discriminating ability and representativeness. Similar assessments were made with this method for different diseases, like fusarium head blight and powdery mildew in wheat (Kadariya et al., 2008; Lillemo et al., 2010), ascochyta blight in faba bean (Rubiales et al., 2012), fusarium wilt and ascochyta blight in chickpea (Pande et al., 2013), fusarium wilt in pigeonpea (Sharma et al., 2016). Among the 42 pure lines, six lines, viz. EA15, EA19, EA35, EA31, EA18 and EA22 showed high level of resistance against leaf rust.

In conclusion, this study has demonstrated the practicality of GGE biplot method in identifying pure lines with stable and low levels of leaf rust disease reactions across environments. Plant breeding studies focused on grain yield require a genotype should have high mean performance and high stability in target environment. Biplot gives a nice graphical display of the which-won-where pattern and makes it easy to identify groups of environments with the same winner and may be used on other types of data relevant to pathology research and plant breeding.

\section{ACKNOWLEDGMENTS}

This research was funded by the Scientific and Technological Research Council of Turkey (TUBITAK, project number 1110255$)$. The authors thank TUBITAK for their financial support.

\section{LITERATURE CITED}

Acorsi, C., T. Guedes, M. Coan, R. Pinto, C. Scapim, C. Pacheco, and Casela, C. 2017. Applying the generalized additive main effects and multiplicative interaction model to analysis of maize genotypes resistant to grey leaf spot. J. Agric. Sci 1-15.

Akin, B., N. Zencirci, and I. Ozseven. 2008. Field resistance of wheat (Triticum aestivum L.) genotypes from different countries to leaf rust (Puccinia triticina). Turk J Agric For. 32: 479-486.

Alam, A. K. M., M. P. Somta, C. Jompuk, P. Chatwachirawong, and P. Srinives, 2014. Evaluation of mungbean genotypes based on yield stability and reaction to mungbean yellow mosaic virus disease. Plant Pathol. J 30: 261-268.

Egesi, C. N., T. J. Onyeka, and R. Asiedu, 2009. Environmental stability of resistance to anthracnose and virus diseases of water yam (Dioscorea alata). Afr. J. Agric. Res 4: 113-118.

Frutos, E., M. P. Galindo, and V. Leiva, 2014. An interactive biplot implementation in $\mathrm{R}$ for modeling genotype-byenvironment interaction. Stoch Environ Res Risk Assess 28: 1629.

Gabriel, K. R. 1971. The biplot graphic display of matrices with application to principal component analysis. Biometrika 58: 453-467.

Gomez, K. A. and A. A. Gomez, 1984.Statistical Procedures for Agricultural Research. John Wiley \& Sons, New York City, USA.

Heitefuss, R. 2011. Wheat Diseases and Pests. J Phytopathol, 159: 324.

Ilker E, F. Aykut Tonk, O. Caylak, M. Tosun, I. Ozmen, 2009. Assesment of Genotype X Environment Interactions for Grain Yield in Mazie Hybrids Using AMMI and GGE Biplot Analyses. Turkish J. of Field Crops 14(2): 123 - 135.

Kadariya, M., K. D. Glover, M. Mergoum and L. E. Osborne, 2008. Biplot analysis of agronomic and Fusarium head blight resistance traits in spring wheat. J Crop Improv. 22: 147170.

Kaplan M., K. Kokten and M. Akcura, 2017. Assessment of Genotype $x$ Trait x Environment interactions of silage maize genotypes through GGE Biplot. Chilean Journal of Agricultural Research 77, $212-217$.

Kempton, R. A. 1984. The use of biplots in interpreting variety by environment interactions. J Agric Sci. 103: 123-135.

Kumar, S., D. K. Baranwal, A. Kumar, R. N. Gupta, and A. Kumar, 2017. $\mathrm{G} \times \mathrm{E}$ Interaction analysis for yield and major diseases in chickpea under rice fallow land of bihar. Environ Ecol. 35: 1238-1243.

Lillemo, M., R. P. Singh, and M. V. Ginkel, 2010. Identification of stable resistance to powdery mildew in wheat based on parametric and non-parametric methods. Crop Sci. 50: 478485 . 
Madden, L.V., P. A. Paul, and P. E. Lipps 2007. Consideration of nonparametric approaches for assessing genotype-byenvironment $(\mathrm{G} \times \mathrm{E})$ interaction with disease severity data. Plant Dis. 91: 891-900.

McCallum, B. D., C. W. Hiebert, S. Cloutier, G. Bakkeren, S. B. Rosa, D. G. Humphreys and B. J. Saville, 2016. A review of wheat leaf rust research and the development of resistant cultivars in Canada. Can. J. Plant Pathol. 38: 1-18.

Mitrović, B., D. Stanisavljević, S. Treskić, M. Stojaković, M. Ivanović, G. Bekavac, M. Rajković, 2012. Evaluation of experimental maize hybrids tested in multi-location trials using AMMI and GGE biplot analyses. Turk. J. Field Crops 17(1): $35-40$

Morgounov, A., M. Keser, M. Kan, M. Kucukcongar, F. Ozdemir, N. Gummadov, H. Muminjanov, E. Zuev and C. O. Qualset, 2016. Wheat landraces currently grown in Turkey: distribution, diversity, and use. Crop Sci. 56: 31123124.

Pande, S., M. Sharma, P. M. Gaur, A. K. Basandrai, L. Kaur, K. S. Hooda, D. Basandrai, T. Kiran, S. Babu, K. Jain and A. Rathore, 2013. Biplot analysis of genotype $\times$ environment interactions and identification of stable sources of resistance to Ascochyta blight in chickpea (Cicer arietinum L.) Australas. Plant Pathol., 42: 561-571.

Parihar, A. K., A. K. Basandrai, A. Sirari, D. Dinakaran, D. Singh, K. Kannan, P. S. Kushawaha, M. Adinarayan, M. Akram, T. K. S. Latha, V. Paranidharan, and S. Gupta, 2017. Assessment of mungbean genotypes for durable resistance to Yellow Mosaic Disease: Genotype $\times$ Environment interactions. Plant Breeding 136: $94-100$.

Peterson R. F., A. B. Campbell, and A. E. Hannah, 1948. A diagrammatic scale for estimating rust intensity on leaves and stems of cereals. Can J Res. 26: 496-500.

Piepho, H. P. 1996. Analyzing genotype environment data by mixed models with multiplicative effects. Biometrics 53:242- 252.
R Core Team, 2013. R: A language and environment for statistical computing. $\mathrm{R}$ Foundation for Statistical Computing, Vienna, Austria.

Rubiales, D., C. M. Avila, J. C. Sillero, M. Hybl, L. Narits, O. Sass, and F. Flores, 2012. Identification and multienvironment validation of resistance to Ascochyta fabae in faba bean (Vicia faba). Field Crops Res. 126: 165-170.

Sandhu, P. S., K. S. Brar, J. S. Chauhan, P. D. Meena, R. P. Awasthi, A. S. Rathi, A. Kumar, J. C. Gupta, S. J. Kolte, and S. S. Manhas, 2015. Host-pathogen interactions of Brassica genotypes for white rust (Albugo candida) disease severity under aided epiphytotic conditions in India. Phytoparasitica 43:197-207.

Sharma, M., R. Ghosh, R. Telangre, A. Rathore, M. Saifulla, D. M. Mahalinga and Y. K. Jain, 2016. Environmental influences on pigeonpea-Fusarium udum interactions and stability of genotypes to Fusarium Wilt. Front Plant Sci. 7:110.

Villegas-Fernández, A. M., J. C. Sillero, A. A. Emeran, J. Winkler, B. Raffiot, J. Tay, F. Flores, and D. Rubiales, 2009. Identification and multi-environment validation of resistance to Botrytis fabae in Vicia faba. Field Crops Res. 114: 84-90.

Yan, W. 2014. Crop variety trials: Data management and analysis. John Wiley and Sons. pp. 349 New York, USA.

Yan, W. and D.E. Falk, 2002. Biplot analysis of host-bypathogen data. Plant Dis, 86: 1396-1401.

Yan, W., L. A. Hunt, Q. Sheng, and Z. Szlavnics, 2000. Cultivar evaluation and mega-environment investigation based on the GGE biplot. Crop Sc.i 40: 597-605.

Yan, W. and M. S. Kang, 2003. GGE Biplot Analysis: A Graphical Tool for Breeders, Geneticists, and Agronomists. CRC Press, Boca Raton, FL.

Yildiz, S. 2011. Rotational and nematicidal effect of lupine (Lupinus albus L.: Leguminosae). Afr. J. Biotechnol. 10: 13252-13255.

Zobel, R. W., M. J. Wright and H. G. Gauch, 1988. Statistical analysis of a yield trial. Agron J, 80: 388-393. 